\title{
Efficient Microchannel Cooling of Multiple Power Devices with Compact Flow Distribution for High Power-Density Converters
}

\author{
Remco van Erp, Student member, IEEE, Georgios Kampitsis, Member, IEEE, Elison Matioli, Member,
} IEEE

\begin{abstract}
In this work, we describe a new approach for compact and energy-efficient cooling of converters where multiple miniaturized microfluidic cold-plates are attached to transistors providing local heat extraction. The high pressure drop associated with microchannels was minimized by connecting these cold-plates in parallel using a compact 3D-printed flow distribution manifold. We present the modeling, design, fabrication and experimental evaluation of this microfluidic cooling system and provide a design strategy for achieving energy-efficient cooling with minimized pumping power. An integrated cooling system is experimentally demonstrated on a $2.5 \mathrm{~kW}$ switched capacitor DC-DC converter, cooling down $20 \mathrm{GaN}$ transistors. A thermal resistance of $0.2 \mathrm{~K} / \mathrm{W}$ was measured at a flow rate of $1.2 \mathrm{ml} / \mathrm{s}$ and a pressure drop of 20 mbar, enabling the cooling of a total of $300 \mathrm{~W}$ of losses in the converter using several $\mathbf{m W}$ of pumping power, which can be realized with small micropumps. Experimental results show a 10fold increase in power density compared to conventional cooling, potentially up to $30 \mathrm{~kW} / \mathrm{l}$. This proposed cooling approach offers a new way of co-engineering the cooling and the electronics together to achieve more compact and efficient power converters.
\end{abstract}

Index Terms - Electronics cooling, high power density, Gallium Nitride (GaN), thermal management, liquid cooling, microfluidics, microchannel cooling, additive manufacturing, 3D printing, switched capacitor converter.

\section{INTRODUCTION}

$\mathrm{T}$ he last decades have seen an ongoing trend of reduction in size of power converters, where roughly every decade the power density of converters doubles [1]. The increasingly tight constraints on size and weight for these power electronics systems has pushed a broad range of innovations, spanning from wide band-gap (WBG) semiconductor devices [2] to new converter topologies [3]. WBG devices, employing gallium nitride $(\mathrm{GaN})$ and silicon carbide $(\mathrm{SiC})$, have a small footprint and high power density owing to their low specific onresistance and high breakdown electric field [4], [5], enabling a compact converter design. Additionally, GaN high electron mobility transistors (HEMTs) can operate at higher frequencies,

This work was supported in part by the European Research Council under the European Union's H2020 program/ERC Grant Agreement No. 679425 and in part by the Swiss Office of Energy Grant No. SI501568-01.

R. van Erp, G. Kampitsis and E. Matioli are with the Power and Wide-BandGap Electronics Research Laboratory, École Polytechnique Fédérale de Lausanne, 1015 Lausanne, Switzerland (e-mail: remco.vanerp@epfl.ch, georgios.kampitsis @epfl.ch; elison.matioli@epfl.ch). enabling the use of smaller passive components which further reduces the converter volume. However, the increased switching losses due to higher switching frequencies and reduced die sizes cause high heat fluxes, surpassing $1 \mathrm{~kW} / \mathrm{cm}^{2}$ [6], [7], which is far beyond the capabilities of conventional cooling methods [8]. Inadequate cooling of these devices causes high junction temperature which degrades their performance and reliability [9], [10].

The thermal challenges become more pronounced in converter topologies with a large number of active components, such as modular [11], [12] and composite topologies [13]. Uneven temperature rise over multiple devices causes hotspots that limit the system performance. The thermal management of these converters closely resembles that of 1980's multi-chip processor modules of mainframe computers, for which elaborate cooling technologies have been developed to simultaneously cool multiple chips [14]. However, such cooling solutions are prohibitively large for contemporary high powerdensity applications. Several modular air-based cooling topologies have been presented to cool down converters with a large number of components in a small form factor [15], [16], but the low heat transfer coefficient of air ultimately limits heat fluxes to roughly $300 \mathrm{~W} / \mathrm{cm}^{2}$ [8]. To achieve higher power density in topologies with a large number of components, highperformance cooling techniques, such as liquid cooling, are required to surpass this limit.

Several high-efficiency liquid cooling strategies have been proposed for cooling of individual power devices, such as impinging coolant on the device [17], [18], as well as flowing coolant through microchannels [19]. The latter can result in state-of-the-art heat fluxes, due its large surface area and high heat transfer coefficient [20]. However, microchannels typically suffer from high pressure drop. Approaches to reduce the pressure drop over microchannel heat sinks have received considerable attention [21]. A promising method is the use of a manifold structure to distribute the flow over the microchannels [22]. This manifold microchannel (MMC) structure reduces the pressure drop, increases the temperature uniformity and increases the heat transfer coefficient [23], [24]. However, although these MMC heat sinks demonstrated in the literature have outstanding capabilities for high heat flux management [25]-[27], the complicated fabrication procedure, consisting of 
multiple bonding steps, has prevented large-scale adoption of this technology.

System-level approaches to employ the easier-to-fabricate parallel straight microchannels in an optimized configuration with minimum pumping requirements have remained largely unexplored. Yet, this could be a crucial step towards larger adaption of microchannels in liquid cooling applications. Consequently, there is currently no standard thermal management solution that can be mounted on a converter, like conventional heat sinks, while providing the high cooling performance of microchannels simultaneously to all active devices.

In this work, we propose a novel compact and energyefficient microfluidic cooling system for power converters with multiple power devices by mounting microchannel cold-plates on each device. The high pressure drop usually associated with microchannels was minimized using a customized compact flow distribution manifold that connects these microfluidic heat-sinks in parallel to a common inlet and outlet. In Section II, a model is presented to determine the optimal microchannel and manifold geometry that maximizes cooling capability and minimizes the required pumping power. Cold-plates were fabricated on silicon using standard clean-room processes, but could easily be replaced by high-throughput fabrication methods such as micro-deformation processes. We demonstrate flow distribution manifolds realized using 3D-printing as well as conventional fabrication methods to demonstrate the possibility of their mass-production in a cost-effective way.

In Section III, the thermal and hydraulic performance of the heat sink is experimentally evaluated. Finally, in Section IV, the cooling module, consisting of 20 silicon microchannel coldplates, is demonstrated on a compact $2.5 \mathrm{~kW}$ switched capacitor DC-DC converter to demonstrate the potential of this new cooling system and its impact on power density. This proposed method provides high performance microchannel cooling in a very compact form-factor with low pressure drop, making it a promising technology for future power converters.

\section{MODELling, DESIGN AND FABRICATION}

In this section the analytical expressions that describe the hydraulic and thermal performance of the heat sink are derived, which are used to optimize the heat sink geometry for energyefficient cooling. First, the cooling performance of an individual cold-plate is evaluated to obtain an optimum design, followed by the design and fabrication of the distribution manifold.

\section{A. Microchannel Cold-Plates}

Fig. 1 shows a schematic overview of the proposed cooling method: A packaged device is mounted on a printed circuit board (PCB) and cooled by a microchannel cold-plate attached on top of the device, separated by a thermal interface material (TIM). We investigate the situation where all dissipated power travels upwards to the microchannel cold-plate, which is the case if the device has a relatively low junction-to-case thermal resistance to the top of the device, and a high junction-to-board thermal resistance.

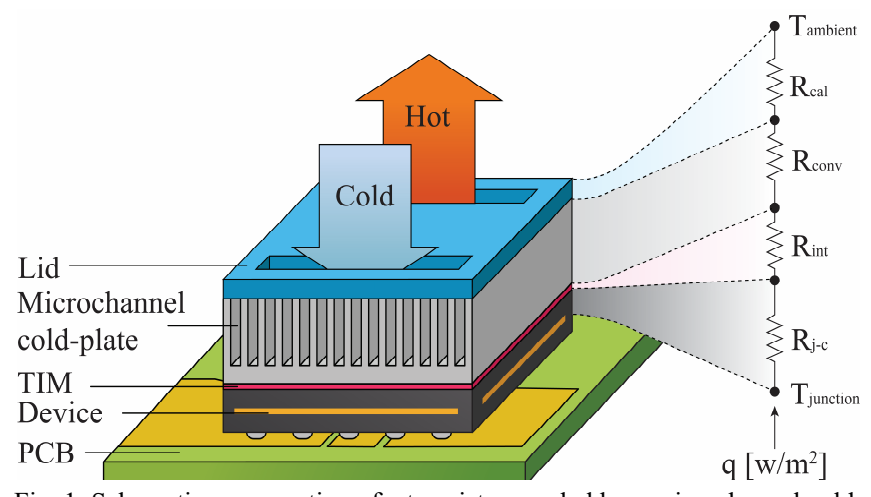

Fig. 1. Schematic cross section of a transistor, cooled by a microchannel coldplate, and an equivalent thermal resistance model.

\section{1) Analytical Model}

The main design objective is to achieve energy efficient cooling, since a reduced pumping power results in a smaller pump size. Cooling efficiency is described by the Coefficient of Performance $(C O P)$, given in (1), defined as the ratio of dissipated power in the in the system, $Q_{\max }$, to the pumping power required, $P$, to keep the junction at a given maximum junction temperature, $\Delta T_{\max }$.

$$
\begin{gathered}
C O P=\frac{Q_{\max }}{P} \\
P=f \Delta p \\
\Delta T_{\max }=Q_{\max } R_{\text {tot }}
\end{gathered}
$$

The pumping power, defined in (2), is the product of the flow rate, $f$, and the pressure drop $\Delta p$. $R_{\text {tot }}$ is the total thermal resistance between the junction of the device and the inlet temperature of the coolant, which relates the heat losses to temperature rise according to (3). From (1)-(3) it is clear that to increase $C O P$, the pressure drop, flow rate and thermal resistance have to be reduced. However, these values are interdependent, so to determine the optimal microchannel geometry, relations between pressure drop, thermal resistance and flow rate are required.

The total thermal resistance, $R_{t o t}$, is the sum of the 4 components shown in the one-dimensional thermal resistance network in Fig. 1. The caloric thermal resistance of the coolant, $R_{c a l}$, given in (4), describes the temperature rise of the coolant between the inlet $\left(T_{\text {in }}\right)$ and the outlet $\left(T_{\text {out }}\right)$ and depends on the flow rate, $f$, the fluid density, $\rho$, and heat capacity, $C_{p}$.

$$
R_{\text {cal }}=\frac{T_{\text {out }}-T_{\text {in }}}{Q_{\max }}=\frac{1}{\rho C_{p} f}
$$

The junction-to-case thermal resistance of the device, $R_{j-c}$, is given by the device manufacturer and the thermal interface resistance, $R_{\text {int }}$, depends on the type of TIM used. The thickness and thermal conductivity of the TIM are important factors that determine $R_{\text {int }}$. The total thermal resistance of the cold-plate consists of the thermal resistance between the surface of the cold plate and the base of the microchannels, and a convection component on the microchannel surface. However, due to the high thermal conductivity of silicon, the conduction component is negligibly small $(<0.01 \mathrm{~K} / \mathrm{W})$. For this reason, the thermal 
resistance of the cold-plate is modeled as only a convective thermal resistance, $R_{\text {conv }}$, as expressed in (5). $h$ is the heat transfer coefficient and $A$ is the total surface area of the microchannels. Using the fin model, previously described in [20], [28]-[30], an expression was derived for the convective thermal resistance, as shown in (5). The geometry of a microchannel is described by the channel width and fin width. A wider channel is favorable for reducing pressure drop, but comes at a cost of a lower fin efficiency. Numerous works in the literature have studied the impact of the proportion of fin to channel width in high aspect ratio microchannels and found a favorable distribution lies generally around 1:1 [31], [32][33]. For that reason, we define $w$ as both the channel and fin width, which simplifies the analytical expressions. $z$ is the channel depth and $N u$ is the Nusselt number. $\epsilon$ is the fin efficiency, calculated using (6), where $k_{s}$ is the thermal conductivity of the heat sink material and $k_{f}$ the thermal conductivity of the fluid.

$$
\begin{aligned}
R_{\text {conv }} & =\frac{1}{h A} \epsilon^{-1}=\left(1+\frac{z}{w}\right)^{-1} \frac{w}{L W k_{f} N u} \epsilon^{-1} \\
\epsilon & =\tanh \left(z \sqrt{\frac{2 h}{k_{s} w}}\right)\left(z \sqrt{\frac{2 h}{k_{s} w}}\right)^{-1}
\end{aligned}
$$

For a given design and its corresponding thermal resistances $\left(R_{\text {conv }}, R_{\text {int }}, R_{j-c}\right)$ and heat load, $Q_{\max }$, the required flow rate to keep the junction temperature rise at $\Delta T_{\max }$ can be calculated using (7). The relationship between pressure drop and flow rate in the microchannel cold plate can be expressed in terms of a hydraulic resistance, $r_{h}$. Considering a cold-plate with $N$ parallel channels, the pressure drop can be calculated using (8) [34]. Eq. (8) does not account for entrance effects, but only considers fully developed laminar flow through the microchannels. The validity of this assumption is investigated later in this work. Combining equation (1)-(8) results in (9), an expression to calculate COP given a certain geometry and heat load. Eq. (9) shows that the coolant requires a high ratio of $\rho^{2} C_{p}^{2} / \mu$, which makes water a good candidate, but this expression does not give an intuitive solution for the optimal channel width. This will be the subject of the next section.

$$
\begin{gathered}
f=\left(\rho C_{p}\left(\frac{\Delta T_{\max }}{Q_{\max }}-R_{\text {conv }}-R_{\text {int }}-R_{j-c}\right)\right)^{-1} \\
\Delta p=r_{h} f=\frac{12 \mu L}{N(1-0.63 w / z) w^{3} z} f \\
C O P=\frac{\rho^{2} C_{p}^{2} Q_{\max }}{r_{h}}\left(\frac{\Delta T_{\max }}{Q_{\max }}-R_{\text {conv }}-R_{\text {int }}-R_{j-c}\right)^{2}
\end{gathered}
$$

\section{2) Evaluation}

Using the aforementioned model, we studied the effect of channel size on the cooling performance of silicon microchannel cold-plates with channel depth $z$ fixed at $400 \mu \mathrm{m}$ and channel width $w$ varying between $10 \mu \mathrm{m}$ and $w=300 \mu \mathrm{m}$. Water was chosen as coolant and a typical value of $0.5 \mathrm{~K} / \mathrm{W}$ was chosen for both $R_{i n t}$ and $R_{j-c}$ [35]. The Nusselt number was

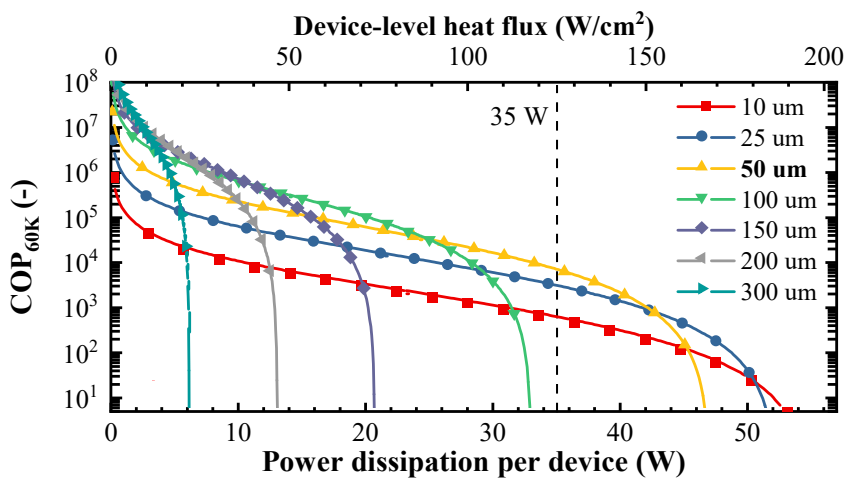

Fig. 2. Calculated COP versus maximum power dissipation per transistor $\left(Q_{\max }\right)$ cooled using the proposed microchannel cold-plate for channel widths varying between $10 \mu \mathrm{m}$ and $300 \mu \mathrm{m}$, considering a maximum temperature rise $\Delta T_{\max }$ of $60{ }^{\circ} \mathrm{C}$ and an inlet temperature of $22^{\circ} \mathrm{C}$. Device-level heat flux was calculated based on a $7 \mathrm{~mm}$ x $4 \mathrm{~mm}$ device size.

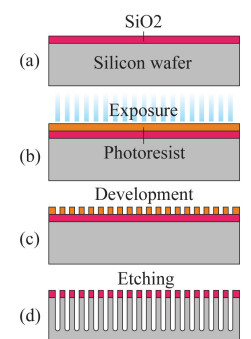

(a)

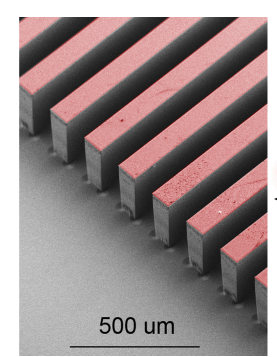

(b)

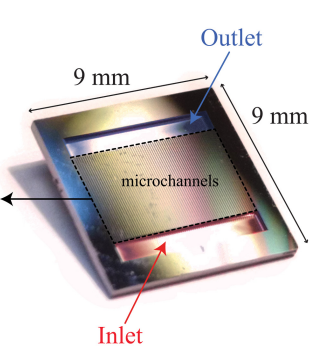

(c)
Fig. 3. (a) Fabrication process of the silicon microchannel cold-plates. (b) SEM image of the microchannels after etching, where false coloring indicates the presence of $\mathrm{SiO}_{2}$. (c) Picture of the cold-plate after dicing.

calculated for a fully developed laminar flow under uniform heat flux condition using the correlation from [34].

Fig. 2 shows the calculated COP versus maximum dissipated power for microchannel cold plates. All curves show the same trend: COP decreases with increasing power due to the higher flow speed required to keep the temperature rise between the junction and the inlet temperature equal to $\Delta T_{\max }=60^{\circ} \mathrm{C}$. After a certain power, a sharp cutoff in COP is observed due to the excessively high flow rates. Reducing the microchannel width results in an increase in $Q_{\max }$ at which this cutoff occurs, because of the reduced $R_{\text {conv }}$, however, at the cost of a lower $\mathrm{COP}$ at lower heat loads. For example, $25 \mu \mathrm{m}$ channels can extract approximately a 5-time higher heat load than $200 \mu \mathrm{m}$ channels but have a 10 times lower COP at low heat loads.

This study reveals that it is important to have an estimation of the power losses in the system to choose the optimal geometry. In our case of a GaN-based soft-switched converter, based on the maximum conduction losses of the used $\mathrm{GaN}$ devices [36], $Q_{\max }$ was estimated at $35 \mathrm{~W}$, making $50 \mu \mathrm{m}$ channels the favorable design choice to obtain the maximum COP based on these assumptions (Fig. 2).

\section{3) Fabrication}

Microchannel cold-plates were fabricated on a 4-inch silicon wafer in a cleanroom environment as illustrated in Fig. 3 (a). A $2 \mu \mathrm{m}$-thick layer of $\mathrm{SiO}_{2}$ was deposited using plasma-enhanced chemical vapor deposition, which functions as a hard mask for 


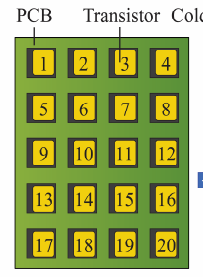

(a)

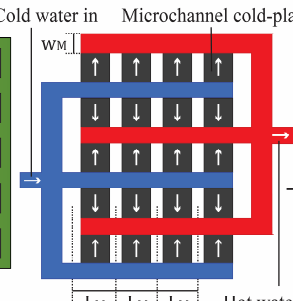

(b)

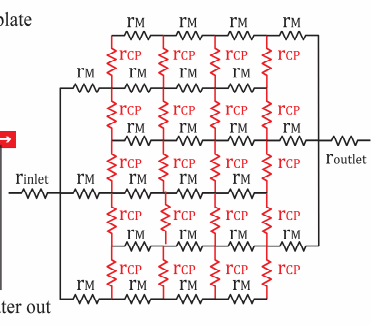

(c)
Fig. 4. (a) Layout of the transistors on a PCB (b) Illustration of the liquid flow through the manifold. Blue and red lines indicate the cold and hot water, respectively. (c) An equivalent hydraulic resistance network of the manifold and the microchannel cold plates.

dry-etching. Channels with widths between $25 \mu \mathrm{m}$ and $100 \mu \mathrm{m}$ were defined using photolithography followed by a dry-etch of the $\mathrm{SiO}_{2}$ using $\mathrm{C}_{4} \mathrm{~F}_{8}$ chemistry. Finally, $400 \mu \mathrm{m}$-deep vertical channels were etched in silicon using the Bosch deep reactiveion etching process. Inlet and outlet ducts were $1 \mathrm{~mm}$ by $7 \mathrm{~mm}$ rectangular openings. Fig. 3 (b) shows a scanning electron microscope (SEM) image of the microchannels after etching. As a final step, the wafer was diced into individual $9 \mathrm{~mm}$ by 9 mm cold-plates, shown in Fig. 3 (c). Due to the inlet and outlet ducts, the cold-plate is slightly larger than the transistor. In order to ensure good contact between these two components, no higher parts should be positioned closely to the transistor.

\section{B. Manifold}

The purpose of the manifold is to distribute liquid to multiple microchannel cold-plates that are in direct contact with the transistors on a PCB, as shown in Fig. 4 (a). Individual coldplates can either be connected in series or in parallel. A series connection guarantees a consistent flow rate over all coldplates, but suffers from a significantly higher pressure drop, as well as a higher temperature rise of the water at an identical flow rate. For this reason, it is favorable to parallelize the cold plates as illustrated in Fig. 4 (b). However, a careful manifold design is required to ensure an equal fluid distribution over all cold-plates and avoid local overheating [37], [38].

\section{1) Analytical model}

The cold-plate manifold was modeled as a network of resistors, illustrated in Fig. 4 (c), where each resistor represents the hydraulic resistance of a specific part of the flow path. The hydraulic resistance of each cold-plate, $r_{C P}$, can be determined using (8), while the hydraulic resistance of the manifold inlet and outlet sections, $r_{M}$, calculated using (10). This equation gives the pressure drop of a square manifold channel section with cross-section $w_{M}$ and length $L_{M}$ [34].

$$
r_{M}=\frac{12 \eta L_{M}}{0.42 w_{M}^{4}}
$$

The currents $I_{C P, i}$ flowing through the resistors marked in red in Fig. 4 (c) represent the flow rate in the cold-plates. Good flow uniformity can be guaranteed if $r_{C P}$ is significantly larger than the sum of the hydraulic resistances over the manifold section. The percentage of variation of current from the mean, $E_{i}$, represents the flow non-uniformity, defined according to (11),

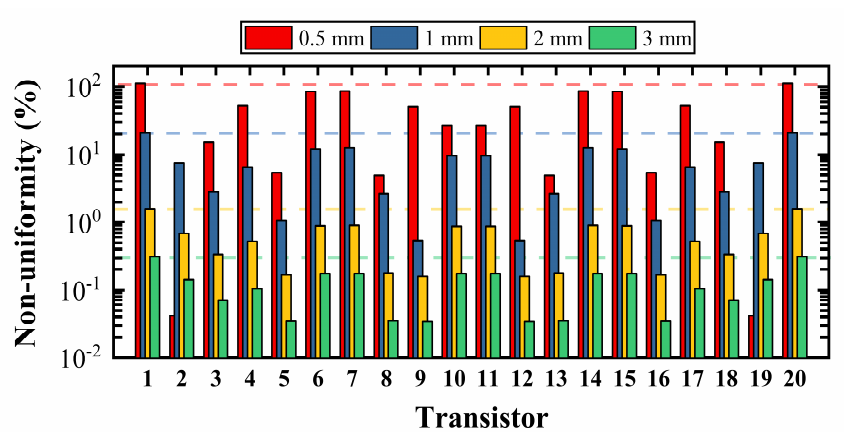

Fig. 5. Flow rate non-uniformity for manifold cross-section width $w_{M}$ varying from $0.5 \mathrm{~mm}$ to $3 \mathrm{~mm}$, defined as the percentage of absolute deviation of flow rate from the mean for all 20 cold-plates.

which is used to assess the quality of the manifold design. A good design should have a low value of $E_{i}$, such that the liquid is equally distributed over all cold-plates.

$$
E_{i}=\left|\frac{20 \cdot I_{C P, i}}{\sum_{j=1}^{20} I_{C P, j}}\right|-1
$$

\section{2) Simulation}

We investigated the flow uniformity of a manifold delivering coolant to a 4 x 5 grid of transistors, as illustrated in Fig. 4 (ab), using the microchannel cold-plates described in Section II.A.3) for each transistor ( $\mathrm{N}=80, w=50 \mu \mathrm{m}$ and $z=300 \mu \mathrm{m}$, $L=6 \mathrm{~mm}$ ). The manifold had equal section length $L_{M}$ of $2 \mathrm{~cm}$ (Fig. 4 (b)), and their cross-section $w_{M}$ was varied from $0.5 \mathrm{~mm}$ to $3 \mathrm{~mm}$ to study its impact on the flow uniformity. LTspice was used to calculate the currents in the resistor network from Fig. 4 (c), which corresponds to the flow distribution through all 20 cold-plates. Fig. 5 shows the percentage of flow nonuniformity, which strongly depends on the manifold channel size. For $w_{M}=0.5 \mathrm{~mm}$, the flow rate non-uniformity is above $100 \%$, whereas for $w_{M}=2 \mathrm{~mm}$ the non-uniformity is limited to approximately $1 \%$. This result clearly shows the importance of properly sizing the manifold for obtaining a uniform distribution of coolants to the cold plates.

Table I summarizes the minimum manifold channel cross sections required to have a flow non-uniformity below $1 \%$ for various microchannel widths. The strong dependence of the hydraulic resistance on the microchannel width leads to a clear advantage in using small dimensional cooling channels for this type of flow parallelization, as a $475 \mu$ m-reduction in microchannel size $w_{\mathrm{c}}$ (from $500 \mu \mathrm{m}$ to $25 \mu \mathrm{m}$ ), enables a 3.5 mm-reduction in manifold channel cross section. In other words, a small reduction in microchannel width results in a large reduction of the volume of the liquid distribution system. Furthermore, since the manifold channel width also limits the

TABLE I

MICROCHANNEL WIDTH AND THE REQUIRED MINIMUM MANIFOLD CHANNEL WIDTH TO HAVE LESS THAN $1 \%$ FLOW NON-UNIFORMITY

\begin{tabular}{ccccc}
\hline \hline $\boldsymbol{w}_{\mathbf{c}}[\boldsymbol{\mu \mathbf { m } ]}$ & $\mathbf{N}$ & $\boldsymbol{z}[\boldsymbol{\mu m}]$ & $\begin{array}{c}\boldsymbol{r}_{\mathbf{C P}} \\
{\left[\mathbf{1 0}^{\mathbf{1 0}} \mathbf{p a ~ \mathbf { ~ m } ^ { - 3 } ]}\right.}\end{array}$ & $\boldsymbol{w}_{\mathbf{M}}[\mathbf{m m}]$ \\
\hline 25 & 160 & 300 & 7.6 & 1.67 \\
$\mathbf{5 0}$ & $\mathbf{8 0}$ & $\mathbf{3 0 0}$ & $\mathbf{2 . 0}$ & $\mathbf{2 . 3 4}$ \\
100 & 40 & 300 & 0.57 & 3.20 \\
250 & 16 & 300 & 0.15 & 4.47 \\
500 & 8 & 300 & 0.08 & 5.19 \\
\hline \hline
\end{tabular}




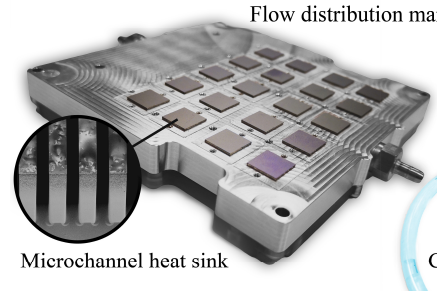

(a)

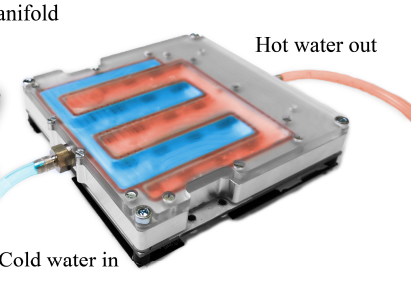

(b)
Fig. 6. Aluminum CNC-machined manifold. (a) Bottom side with 20 silicon microchannel cold plates attached to the manifold. (b) Top side with a polycarbonate lid.

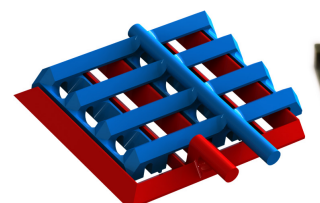

(a)

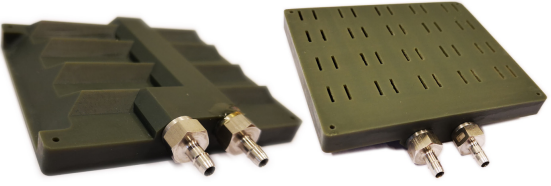

(b) (c)
Fig. 7. 3D-printed manifold. (a) CAD model of the flow path inside the manifold. Blue and red regions indicate the cold and hot water flow, respectively. (b) Top side of the manifold after 3D printing. (c) Bottom of the manifold which shows the slits that connect the manifold to the microchannel cold-plates.

minimum spacing between the cold plates, this reduction allows the transistors to be positioned closer together.

\section{3) Fabrication}

Two flow distribution manifolds were fabricated based on the design rules from the previous simulation. The first manifold, shown in Fig. 6 (a), was realized using Computer Numerical Controlled (CNC) machining and consists of three pieces: an aluminum body, a polycarbonate lid and a silicone gasket to provide leak-tight seal. This simple design can be easily fabricated by injection molding for low-cost mass manufacturing. The bottom side of the manifold contains 40 slits connected to the inlet and outlet of 20 silicon microchannel cold plates. The cold-plates were connected to the manifold using a water-resistant double-sided adhesive, which was lasercut to size. Fig. 6 (b) shows the top side of the manifold where the red and blue colors indicate the hot and cold water, respectively.

A more compact manifold was fabricated using stereolithography (SLA) 3D printing. The possibility to 3D print the manifold is very interesting for rapid prototyping together with the electronic design. This way, the geometry of the cold-plate defines the cooling performance whereas the manifold defines the distribution of the coolant. Additionally, by removing the constraints of conventional fabrication methods, more compact designs can be realized. A network of overlapping inlet and outlet channels was designed, shown in the computer-aided design (CAD) model of Fig. 7 (a), where the blue and red colored sections indicate the hot and cold water, respectively. Such a design cannot be realized using conventional CNC machining, but additive manufacturing enables the realization of such a monolithic structure. High temperature resist was used (EnvisionTEC HTM140) which can withstand temperatures up to $140{ }^{\circ} \mathrm{C}$. The sidewalls of all

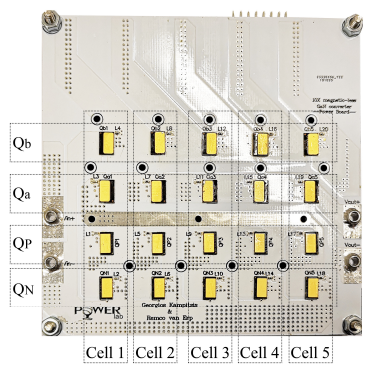

(a)

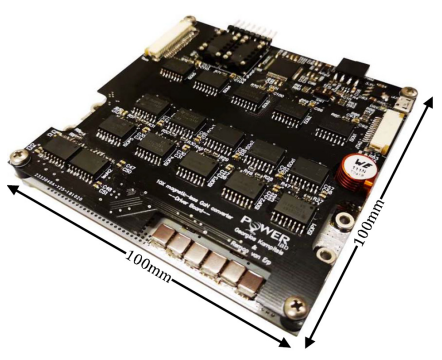

(b)
Fig. 8. 10x step up DC-DC converter consisting of two board: (a) Power board, containing $20 \mathrm{GaN}$ transistors in a $5 \mathrm{x} 4$ grid. (b) Control board.

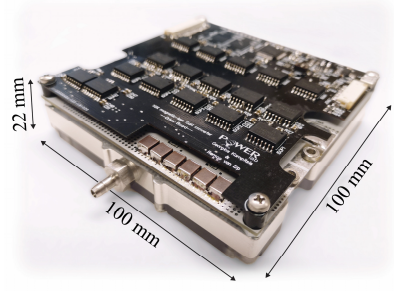

(a)

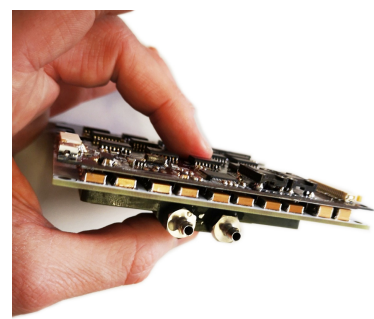

(b)
Fig. 9. Full system (a) With the aluminum CNC machined heat sink, and (b) with the 3D-printed manifold heat sink.

channels were angled at 45 degrees to print the structure without internal support material, as this would be impossible to remove from the monolithic structure. Fig. 7 (b) and Fig. 7 (c) show the manifold after printing. The slits visible in Fig. 7 (c) connect to the inlet and outlet of the silicon microchannel cold-plates. The total volume of this manifold is only $35 \mathrm{~cm}^{3}$.

\section{Converter}

The heat sink was designed together with the switched capacitor DC-DC converter shown in Fig. 8. This $n \mathrm{X}$-converter, previously described in [39], is a modular multi-level voltage multiplier with a fixed even step-up ratio $n$, where $n / 2$ indicates the number of cells required. Each cell of this converter consists of 4 transistors, resulting in a total of $2 n$ transistors [40]-[42]. In this work, a 10x step-up converter was used with a total of $20 \mathrm{GaN}$ transistors, as shown in Fig. 8 (a). This topology is an ideal test bed to evaluate the proposed cooling system, as it contains no magnetic components. The 20 transistors are therefore the major power-dissipating components, and the maximum output power is defined by how well these devices are cooled down.

The selected GaN transistors (GS61008T, GS66508T) have a thermal pad on the top-side resulting in a low junction-to-top thermal resistance of $0.55 \mathrm{~K} / \mathrm{W}$ [35], [36]. A temperature sensor was placed directly next to each transistor, sharing the same copper pad, to monitor each individual transistor temperature in real-time. The top side of the converter, shown in Fig. 8 (b) contains all gate drivers, isolated power supplies and a microprocessor to generate the pulse width modulation (PWM) signals. Fig. 9 (a) shows the converter with the aluminum CNC machined heat sink. An alumina-filled silicone TIM with a thermal conductivity of $12 \mathrm{~W} / \mathrm{mK}$ (T-Global TGX) was placed on each transistor. The power board was fixed on the heat sink 


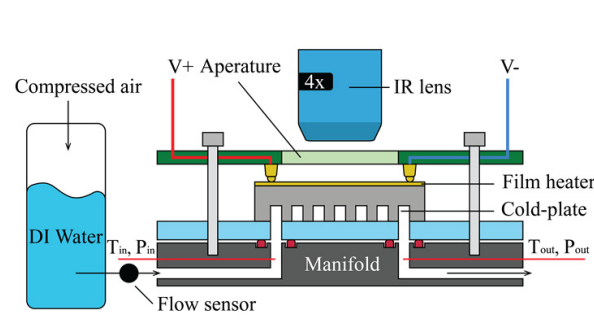

(a)

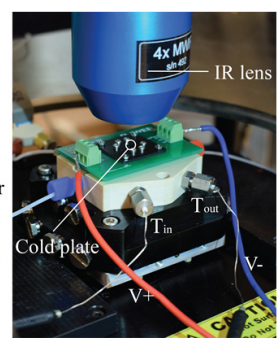

(b)
Fig. 10. (a) Schematic illustration of the cooling performance evaluation setup. (b) Picture of the test section underneath an IR camera.

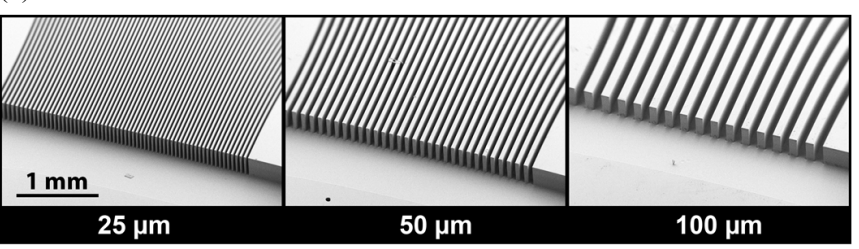

(a)

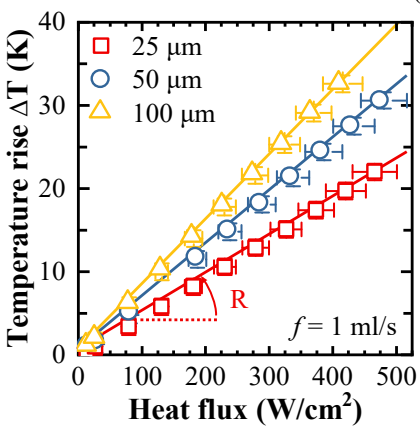

(b)

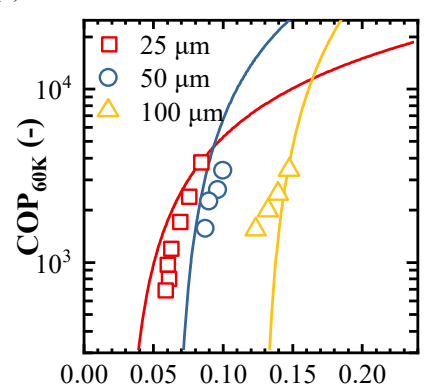

Thermal resistance $\left(\mathrm{cm}^{2} \mathrm{~K} / \mathrm{W}\right)$

(c)
Fig. 11. (a) SEM images of the 3 evaluated microchannel cold-plates. (b) Temperature rise between the inlet temperature of the coolant and the surface of the cold-plate versus heat flux. Slope of the linear fit through the data points indicates the thermal resistance, $R$. The coolant inlet temperature was $25^{\circ} \mathrm{C}$. (c) $\mathrm{COP}$ versus thermal resistance. Experimental measurements are indicated by the markers and the lines indicate the results using the analytical model from (9).

with 15 screws to ensure a good and repeatable thermal contact between each cold-plate and transistor. The converter with 3Dprinted manifold heat sink is shown in Fig. 9 (b). This system is only $200 \mathrm{~cm}^{3}$ and still includes empty space for future integration of a pump within this volume.

\section{EXPERIMENTAL EVALUATION OF THE HEATSINK}

\section{A. Microchannel Cold-Plates}

A test setup was developed to experimentally investigate the performance of microchannel cold-plates of various channel dimensions. This setup, illustrated in Fig. 10 (a), contains a pressure regulator (Elveflow OB1 MK3) that pressurizes a reservoir with deionized (DI) water. The DI water flows, through a flow meter into the test section that contains an individual microchannel cold-plate. This test setup includes 2 calibrated thermocouples that measure the water temperature before and after the cold-plate and a pressure sensor to determine the pressure drop over the cold-plate.

To investigate the properties of each individual cold plate in this setup, a thin metal film was deposited on the backside of
TABLE II

DIMENSIONS AND MEASUREMENTS OF MICROCHANNEL COLD-PLATES

\begin{tabular}{cc|c|c|c}
\hline \hline $\mathbf{w}[\boldsymbol{\mu m}]$ & $\mathbf{z}[\boldsymbol{\mu m}]$ & $\mathbf{D}_{\mathbf{h}}[\boldsymbol{\mu m}]$ & $\mathbf{R}_{\text {conv }}\left[\mathbf{c m}^{2} \mathbf{K} / \mathbf{W}\right]$ & $\mathbf{h}_{\text {eff }}\left[\mathbf{W} / \mathbf{m}^{2} \mathbf{K}\right]$ \\
25 & 400 & 47 & $3.3 \cdot 10^{-2}$ & $3.03 \cdot 10^{5}$ \\
50 & 400 & 89 & $6.9 \cdot 10^{-2}$ & $1.45 \cdot 10^{5}$ \\
100 & 400 & 160 & $1.1 \cdot 10^{-1}$ & $9.09 \cdot 10^{4}$ \\
\hline
\end{tabular}

the cold-plate by electron-beam physical vapor deposition to function as a resistive heating element emulating the power dissipated by each transistor. This heating element allows an easy variation of the dissipated power, and the absence of $R_{i n t}$ and $R_{j-c}$ enables an accurate measurement of the convective thermal resistance.

A PCB connected the heating element to a regulated power supply (TTI QPX1200S) and the temperature at the surface of the cold-plate was measured using an infrared (IR) microscope (QFI InfraScope). The IR microscope was pixel-by-pixel calibrated by flowing water at various fixed temperatures through the cold-plate using a thermostatic bath. Power dissipation was determined using an energy balance to account for any heat that leaks out of the setup by convection to the ambient or by conduction through the test section. This calculated power was within $95 \%$ of the total dissipated electrical power, which confirms a sufficiently isolated test setup. Thermal resistance was determined by taking the slope of the surface temperature rise versus power dissipation. Finally, the COP is calculated using (12):

$$
C O P=\frac{\Delta T_{\max }}{R} \frac{1}{\Delta p f}
$$

Fig. 11 (a) shows SEM images of the 3 cold-plates evaluated in this study $\left(w_{c}=25 \mu \mathrm{m}, 50 \mu \mathrm{m}\right.$ and $\left.100 \mu \mathrm{m}\right)$. The experimental temperature rise between the surface of the cold-plate and the inlet temperature of the coolant versus power dissipation for these cold-plates at a flow rate of $1 \mathrm{ml} / \mathrm{s}$ is shown in Fig. 11 (b). The slope of the linear fit through these measurement points gives the thermal resistance, $R$. The experimental COP, calculated using (12), is shown in Fig. 11 (c) along with lines corresponding to the analytical model from (9), confirming that smaller sized channels can handle higher heat loads more efficiently. A reasonable match between the experimental results and the model was obtained, which validates our initial design approach. Based on the experimental results, $R_{\text {conv }}$ was determined to be approximately $3.3 \cdot 10^{-2} \mathrm{~cm}^{2} \mathrm{~K} / \mathrm{W}, 6.9 \cdot 10^{-2}$ $\mathrm{cm}^{2} \mathrm{~K} / \mathrm{W}$ and $1.1 \cdot 10^{-1} \mathrm{~cm}^{2} \mathrm{~K} / \mathrm{W}$ for $w_{c}=25 \mu \mathrm{m}, 50 \mu \mathrm{m}$ and 100 $\mu \mathrm{m}$, respectively. Table II provides an overview of dimensions, thermal resistances and base-effective heat transfer coefficients.

\section{B. Junction temperature estimation}

To properly determine the junction to inlet thermal resistance, the junction temperature has to be estimated. Electrical methods that relate the change in on-resistance to temperature are commonly used for this purpose [43]. However, these methods cannot be used to monitor the junction temperature in real-time during converter operation. Alternatively, IR measurements can provide junction temperature information during normal operation of the device given that that the setup permits visual monitoring and a good correlation between junction and case temperature is available [44]. In our prototype, however, the transistors are covered on 
both sides between the PCB and the heat sink. As such, IR measurements could not be employed here.

To estimate the junction temperature in this work, temperature sensors positioned directly next to the transistor on the same copper pad were utilized. Usually, when a large heat flux travels downwards from the device to the PCB, a large temperature difference can be found between the junction and such sensor, determined by the junction-to-board thermal resistance. However, in our design we neglect the heat flux traveling to the PCB and assume that all heat flux moves upwards to the cold-plate. In that case, due to the absence of heat flux below the junction, an isothermal region is obtained between the chip and the board, such that a temperature sensor accurately represents the junction temperature.

The validity of this approach dependents on two assumptions: 1) All heat flux travels towards the cold plates and 2) the neighboring transistors do not affect the temperature reading. These assumptions were tested by performing a numerical simulations of steady-state conductive heat transfer in COMSOL, by solving Poisson's equation $\left(-k \nabla^{2} T=q\right)$ in 3D. A single row of the converter, consisting of 5 transistors was considered. The transistor was modeled as a 3-layer structure, as shown in Fig. 12 (a). A volumetric heat source represents the junction, and the junction-to-top and junction-to-board thermal resistance where obtained by giving the appropriate thermal

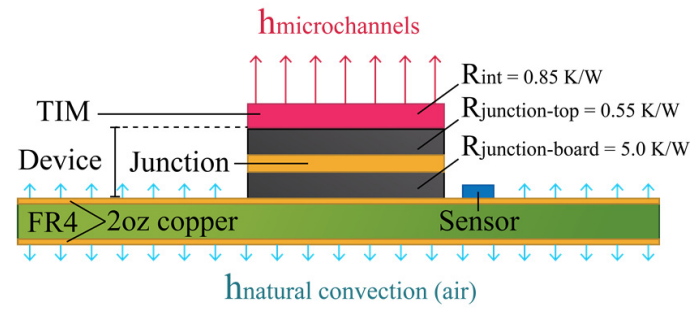

(a)

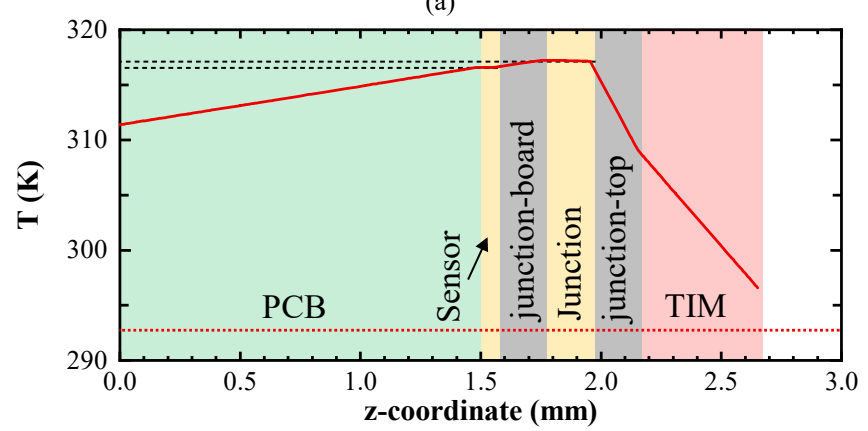

(b)

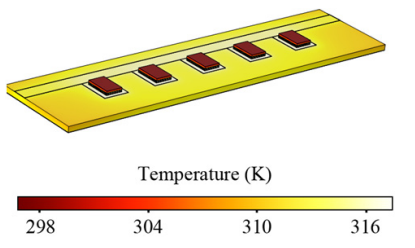

(c)

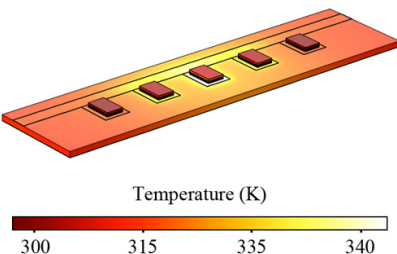

(d)
Fig. 12. (a) Schematic model of the numerically simulated structure. (b) Temperature profile through the center of a device and the PCB in scenario 1. (c) Temperature (in $\mathrm{K}$ ) of the simulated section of the converter in scenario 1 . (d) Temperature (in K) of the simulated section of the converter in scenario 2.
TABLE III

SIMULATION RESULTS

\begin{tabular}{|c|c|c|c|c|c|c|}
\hline \multirow{2}{*}{$\mathbf{S}$} & \multirow{2}{*}{ device } & \multirow{2}{*}{$Q[\mathrm{~W}]$} & \multicolumn{2}{|c|}{$\Delta T[\mathrm{~K}]$} & \multirow{2}{*}{$\varepsilon[\%]$} & \multirow{2}{*}{$R_{t h}[\mathbf{K} / \mathbf{W}]$} \\
\hline & & & Junction & Sensor & & \\
\hline \multirow{5}{*}{1.} & 1 & 15 & 24.1 & 23.3 & 3.3 & 1.61 \\
\hline & 2 & 15 & 24.1 & 23.4 & 2.9 & 1.61 \\
\hline & 3 & 15 & 24.2 & 23.5 & 2.9 & 1.61 \\
\hline & 4 & 15 & 24.1 & 23.4 & 2.9 & 1.61 \\
\hline & 5 & 15 & 24.1 & 23.3 & 3.3 & 1.61 \\
\hline \multirow{5}{*}{2.} & 1 & 10 & 16.4 & 16.6 & 1.2 & 1.64 \\
\hline & 2 & 20 & 32.1 & 31 & 3.4 & 1.61 \\
\hline & 3 & 30 & 47.6 & 45 & 5.5 & 1.59 \\
\hline & 4 & 20 & 32.1 & 31 & 3.4 & 1.61 \\
\hline & 5 & 10 & 16.4 & 16.6 & 1.2 & 1.64 \\
\hline
\end{tabular}

conductivity to the top and bottom layer, respectively. The TIM was modeled as a $1 \mathrm{~mm}$ thick solid block on top of the transistor with a thermal conductivity chosen to obtain a $R_{\text {int }}$ of $0.85 \mathrm{~K} / \mathrm{W}$. The microchannel heat sink was modeled as a convective heat transfer boundary condition of $10^{5} \mathrm{~W} / \mathrm{m}^{2} \mathrm{~K}$, corresponding to the values obtained for $100 \mu \mathrm{m}$ microchannels (Table II). The PCB was modeled as a $1.6 \mathrm{~mm}$ thick block of FR4, with $70 \mu \mathrm{m}$ of copper on either side. All exposed sides of the PCB were subjected to natural convection with a heat transfer coefficient of $10 \mathrm{~W} / \mathrm{m}^{2} \mathrm{~K}$ and $293 \mathrm{~K}$ was set as ambient temperatures in the simulations. The remaining surfaces, i.e. the sidewalls of the chip were given adiabatic boundary conditions. Heating of the coolant was not considered in this simulation, which corresponds to the hypothetical scenario of an infinitely high flow rate. A mesh with $7 \cdot 10^{5}$ degrees of freedom (DOF) was used, and further refinement did not result change the obtained values.

Two scenarios where considered in the simulations. Scenario 1 considers an equal power dissipation of $15 \mathrm{~W}$ per transistor. Fig. 12 (b) shows the temperature in the cross-section through the center of an individual device. As can be seen, a large temperature gradient is observed between the junction and the top of the TIM, whereas the temperature difference between the junction and the top copper layer on the PCB is very small. Table III summarizes the numerical results of this simulation. It shows that in scenario 1, which corresponds to normal operation of the converter, the difference between the junction temperature and the sensor has a maximum value of $3.3 \%$. Fig. 12 (d) shows the temperature of the modeled section of the converter in scenario 1.

Scenario 2 considers a worst case scenario with a very uneven power distribution. Transistor 3 , in the center, has a power dissipation of $30 \mathrm{~W}$. Transistor 2 and 4 are subjected to a power dissipation of $20 \mathrm{~W}$, whereas transistors 1 and 5 on the outside are subjected to $10 \mathrm{~W}$ of losses. The uneven distribution of losses causes a temperature gradient over the $\mathrm{PCB}$, resulting in cross-talk between the temperature rises of the individual devices. Fig. 12 (e) shows the temperature in scenario 2, with a higher temperature in the center as expected. As can be seen in Table III, the maximum discrepancies between the junction and sensor temperature in this worst-case scenario was $5.5 \%$. Given the limitations of available methods, the $5.5 \%$ error in worstcase scenario conditions was considered acceptable in estimating the junction temperature. 


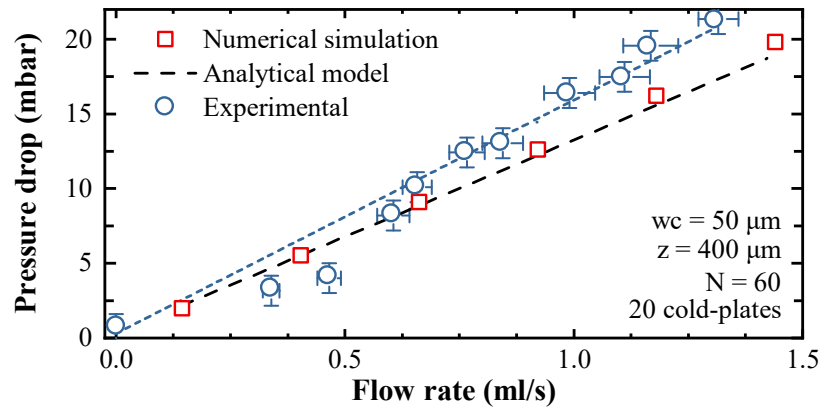

Fig. 13. Experimentally observed and predicted pressure drop versus flow rate of the manifold heat sink. Numerical simulation were performed in COMSOL included the inlet and outlets of the cold-plates. Analytical prediction was based on (9), considering fully developed laminar flow without inlet and outlet effects. Blue dashed line is a linear fit through the experimental results.

\section{Manifold Heat Sink}

The hydraulic performance of the heatsink was measured using pressure sensors (Elveflow MPS) mounted inside the inlet and outlet manifold region. Fig. 13. Shows the experimentally observed pressure drop versus flow rate, as well as the predicted pressure drop based on the analytical model in (8). As indicated before, (8) neglects the pressure drop due to the inlet and outlet contraction and expansion, as well as any developing flow phenomena. Numerical simulations were performed in COMSOL to test the validity of (8), by solving the steady-state Navier-Stokes equation on the 3D domain of an individual microchannel with inlet and outlet contractions $(\rho(\boldsymbol{u} \cdot \nabla) \boldsymbol{u}=\boldsymbol{\nabla} \cdot(-$ $\left.\left.p \mathrm{I}+\mu\left(\nabla \boldsymbol{u}+(\nabla \boldsymbol{u})^{\mathrm{T}}\right)\right)+\mathrm{F}\right)$. Laminar flow and incompressibility were assumed, and no-slip boundary conditions on all physical walls, a symmetry boundary condition on the virtual boundaries of the inlet and outlet ducts, as well as a zero-pressure boundary condition on the outlet were applied. A fully developed inflow with varying flow rate was fixed at the inlet of the chip. A mesh with $9 \cdot 10^{5}$ DOF was used, and further refinement did not result change the obtained values. The results are compared in Fig. 12 , showing a good correspondence between numerical and analytical results. The measured flow resistance was $15.7 \pm 0.51$ mbar $\cdot \mathrm{s} / \mathrm{cm}^{3}$, compared to a predicted $13.0 \mathrm{mbar} \cdot \mathrm{s} / \mathrm{cm}^{3}$ based on the analytical model.

The exact power dissipation per transistor must be known to determine the total thermal resistance (as indicated in Fig. 1). For this purpose, the converter was operated such that all transistors were operating in continuous conduction mode, and all power was equally dissipated over the 20 transistors. By sweeping the power dissipation and measuring the temperature

TABLE IV

MEASUREMENT CONDITIONS

\begin{tabular}{ccccccc}
\hline \hline $\begin{array}{c}\boldsymbol{f} \\
{[\mathbf{m l} / \mathbf{s}]}\end{array}$ & $\begin{array}{c}\boldsymbol{v} \\
{[\mathbf{c m} / \mathbf{s}]}\end{array}$ & $\begin{array}{c}\boldsymbol{R} \boldsymbol{e} \\
{[-]}\end{array}$ & $\begin{array}{c}\boldsymbol{R}_{\boldsymbol{t h}} \\
{[\mathbf{K} / \mathbf{W}]}\end{array}$ & $\begin{array}{c}\boldsymbol{R}^{{ }^{t h}} \\
{\left[\mathbf{c m}^{2} \mathbf{K} / \mathbf{W}\right]}\end{array}$ & $\begin{array}{c}\Delta \boldsymbol{p} \\
{[\mathbf{m b a r}]}\end{array}$ & $\begin{array}{c}\mathbf{C O P}_{\mathbf{6 0}} \\
{[-]}\end{array}$ \\
\hline 0.57 & 2.06 & 3.3 & 8.93 & 2.50 & 9.05 & $2.57 \cdot 10^{5}$ \\
0.75 & 2.69 & 4.3 & 7.35 & 2.06 & 11.8 & $1.83 \cdot 10^{5}$ \\
0.91 & 3.25 & 5.2 & 6.20 & 1.74 & 14.3 & $1.49 \cdot 10^{5}$ \\
1.19 & 4.26 & 6.8 & 5.07 & 1.42 & 18.7 & $1.06 \cdot 10^{5}$ \\
1.39 & 4.97 & 8.0 & 4.86 & 1.36 & 21.9 & $8.11 \cdot 10^{4}$ \\
1.61 & 5.76 & 9.2 & 4.46 & 1.26 & 25.3 & $6.55 \cdot 10^{4}$ \\
1.73 & 6.20 & 9.9 & 4.33 & 1.21 & 27.2 & $5.86 \cdot 10^{4}$ \\
\hline \hline
\end{tabular}

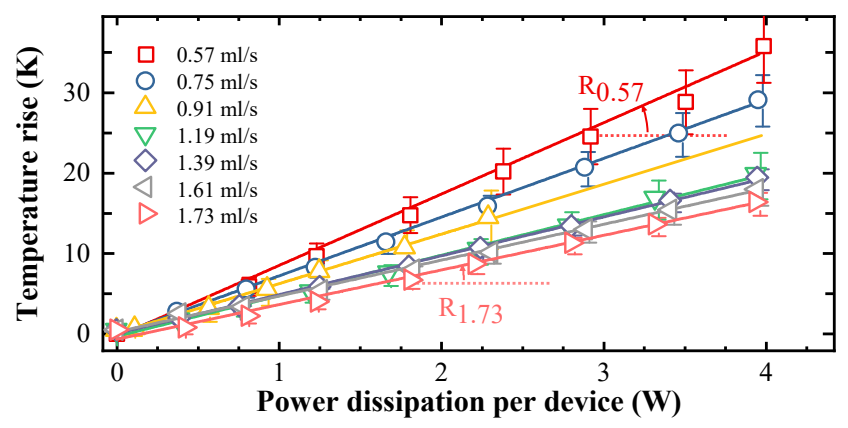

Fig. 14. Temperature rise between the device and the coolant inlet temperature versus power dissipation. Lines indicate a linear fit and the slope gives the total thermal resistance. Flow rates are combined values for all 20 devices, whereas power dissipation was measured per device. Error bars indicate the standard deviation of all 20 temperatures measured on the converter per data point.

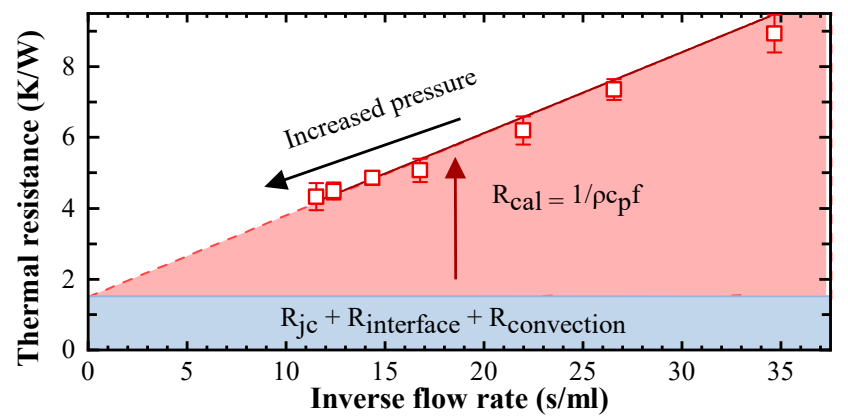

Fig. 15. Thermal resistance versus flow speed per cold-plate. The red area indicates the caloric thermal resistance, $R_{\text {cal }}$, whereas the blue part under the curve is the fixed part of the thermal resistance at a theoretical infinite flow rate.

rise of the device, the thermal resistance was obtained from the slope of temperature rise versus power dissipation. This measurement was repeated for multiple flow rates, to isolate the flow rate-dependent caloric resistance $\left(R_{\text {cal }}\right)$ from the fixed geometry-dependent thermal resistance $\left(R_{\text {conv }}+R_{\text {int }}+R_{j-c}\right)$. By combining this information with the previously determined $R_{c o n v}$, and the datasheet values of $R_{j-c \text {, we estimated all thermal }}$ resistances in our system, which is valuable for optimization purposes.

Fig. 14 shows the temperature rise between the device and the inlet temperature of the coolant versus power dissipation per device. The temperature rise shows a linear relationship with dissipated power, the slope of which represents the thermal resistance. The thermal resistance was determined for 7 flow rates, between $0.57 \mathrm{ml} / \mathrm{s}$ and $1.73 \mathrm{ml} / \mathrm{s}$. Table IV shows an overview of all measurement conditions and the obtained values of thermal resistance, pressure drop and COP calculated using (12), based on a junction temperature rise of $60 \mathrm{~K} . v$ is the average velocity of the liquid inside the microchannels and $R e$ is the non-dimensional Reynold's number, clearly indicating laminar flow conditions as well as a negligible entrance length. 


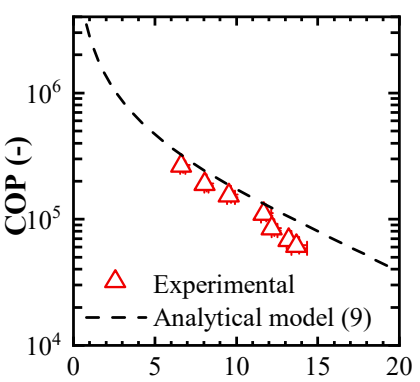

Power dissipation per device $(\mathrm{W})$

(a)

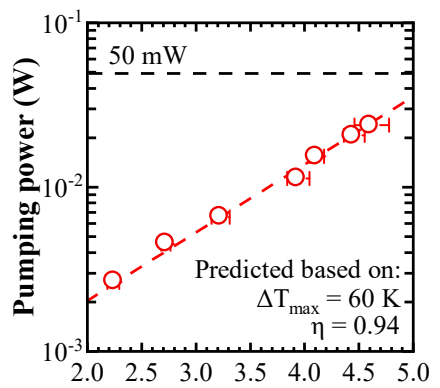

Transferred power $(\mathrm{kW})$

(b)
Fig. 16. (a) Comparison of COP versus maximum power dissipation between the predicted COP from (9) and the experimentally derived COP of the fabricated manifold heat sink. (b) Pumping power versus predicted converter output power based on $\Delta T_{\max }=60 \mathrm{~K}$.

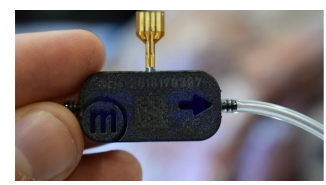

(a) $50 \mathrm{~mW}$

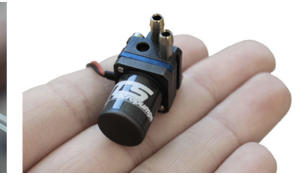

(b) $1 \mathrm{~W}$

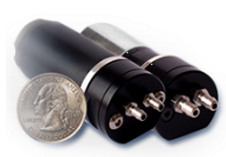

(c) $10 \mathrm{~W}$
Fig. 17. Representative pumps for selected power ratings. (a) $50 \mathrm{~mW}$ : Bartels Mikrotechnik GmbH, (b) $1 \mathrm{~W}$ : TCS Micropumps Ltd, (c) $10 \mathrm{~W}$ : Flight Works, Inc.

The flow rate dependent thermal resistances, extracted from the slope of the curves in Fig. 14, are plotted in Fig. 15. The contribution of the thermal resistance marked in red indicates the caloric thermal resistance, showing a clear $f^{-1}$ relation $\left(R_{c a l}\right.$ $\left.=1 / \rho C_{p} f\right)$. The contribution marked in blue in Fig. 15 corresponds to the fixed part of the thermal resistance $\left(R_{\text {conv }}+\right.$ $R_{\text {int }}+R_{j-c}$ ), which is approximately $1.45 \pm 0.086 \mathrm{~K} / \mathrm{W}$, which corresponds to the predicted thermal resistance at infinite flow speed. The junction to case thermal resistance is provided by the manufacturer $(0.55 \mathrm{~K} / \mathrm{W})$ and the convective thermal resistance was determined in the previous section to be approximately $0.25 \mathrm{~K} / \mathrm{W}$ (see Fig. 11), corresponding to a baseeffective heat transfer coefficient of $1.4 \cdot 10^{5} \mathrm{~W} / \mathrm{m}^{2} \mathrm{~K}$. We can now deduce that the interface thermal resistance is approximately $0.65 \mathrm{~K} / \mathrm{W}$. All contributions to the total thermal resistance are summed up in Table $\mathrm{V}$.

Fig. 16 (a) shows the experimentally obtained COP versus the power dissipation per device for $\Delta T_{\max }=60 \mathrm{~K}$. The dashed line corresponds to the analytical model of (9). As can be seen, a reasonable correspondence was obtained between the two, thus validating the modeling and optimization approach in Section II. The slightly lower COP at higher power levels can be accounted to a higher pressure drop at high flow rates than predicted by the model (Fig. 13). Fig. 16 (b) shows the required pumping power at different expected loading of the converter, based on a $94 \%$ efficiency of the converter and assuming an equal distribution of losses. Based on these assumptions, up to $5 \mathrm{~kW}$ of transferred power can be delivered while requiring less than $50 \mathrm{~mW}$ of pumping power. Fig. 17 shows and overview of commercially available pumps in the low-power range. The high COP and resulting low pumping power requirements enables the use of small piezoelectric micropumps which helps achieving high system-level power density.
At sufficiently high flow-rates, a thermal resistance as low as $1.45 \mathrm{~K} / \mathrm{W}$ per device could potentially be obtained. For a maximum device temperature rise of $60 \mathrm{~K}$, a predicted $41 \mathrm{~W}$ per transistor could be cooled down using this approach, which corresponds to a combined $820 \mathrm{~W}$ of losses that can be extracted from this system. If all losses were to be distributed equally over the 20 transistors on a converter with $94 \%$ efficiency, this would enable a predicted maximum transferred power of $14 \mathrm{~kW}$. An interesting finding from Table $\mathrm{V}$ is that the TIM dominates the thermal resistance, which stresses the importance of improving the thermal interface resistance to achieve a lower $R_{\text {total. }}$

\section{LIQUID COOLED DC-DC CONVERTER}

\section{A. Converter operation}

The microchannel cold-plate manifold heat sink was evaluated during operation of the converter for an output power up to $2.5 \mathrm{~kW}$, while the flow rate was fixed at $1 \mathrm{ml} / \mathrm{s}$. Fig. 18 shows the temperature rise per transistor during operation of the converter at a loading of $1 \mathrm{~kW}$. Since the total mass of the silicon cold-plates is low, the system has a small thermal inertia and thus steady state is obtained within a few minutes. A large spread in maximum temperature rise was observed among different transistors. At $1 \mathrm{~kW}, \mathrm{Q}_{\mathrm{a} 4}$ reached a steady state temperature rise of $25 \mathrm{~K}$ whereas the temperature rise on $\mathrm{Qp}_{\mathrm{p}}$ did not surpass $8 \mathrm{~K}$. Fig. 19 shows the steady state temperature map at $1 \mathrm{~kW}$ transferred power. A clear pattern can be seen where the $Q_{a}$ and $Q_{b}$ transistors heat up more than the $Q_{P}$ and $\mathrm{Q}_{\mathrm{N}}$ transistors. This is not in agreement with the assumptions from Section III, where all losses were distributed equally over the transistors, as the converter was not designed to have uniform losses. This large spread in temperature can be accounted by the difference between the 2 types of power devices used and the electrical design of the converter, as well as the uneven stress on the devices due to the selected converter topology [39]. Despite this large temperature spread, the temperatures rise of all devices stayed well below the limit of $60 \mathrm{~K}$ over the entire range of measured transferred power up to $2.5 \mathrm{~kW}$.

\section{B. Comparison with conventional cooling}

To compare the thermal performance with conventional heat sinks, we repeated the experiment using a $10 \mathrm{~cm} \times 10 \mathrm{~cm}$ x 4.5 $\mathrm{cm}$ aluminum heat sink on top of the converter with a thermal resistance of $1 \mathrm{~K} / \mathrm{W}$ at natural convection. Note that this value is 10x higher than the thermal resistance of the microfluidic heat sink, whereas its volume is 13 times larger. This shows that the microfluidic heat sink is 130 times more volume efficient than TABLE V

BREAKDOWN OF THE TOTAL THERMAL RESISTANCE

\begin{tabular}{|c|c|c|}
\hline THERMAL RESISTANCE & $R[\mathrm{~K} / \mathrm{W}]$ & $\varepsilon[\mathbf{K} / \mathbf{W}]$ \\
\hline Junction to case $\quad R_{j-c}$ & 0.55 & 0.028 \\
\hline Thermal Interface $R_{\text {int }}$ & 0.65 & 0.10 \\
\hline Convection $\quad R_{\text {conv }}$ & 0.25 & 0.05 \\
\hline Caloric $\quad R_{\text {cal }}$ & $1 / \rho C_{p} f$ & - \\
\hline Total $R_{\text {total }}$ & $1.45+1 / \rho C_{p} f$ & 0.086 \\
\hline
\end{tabular}




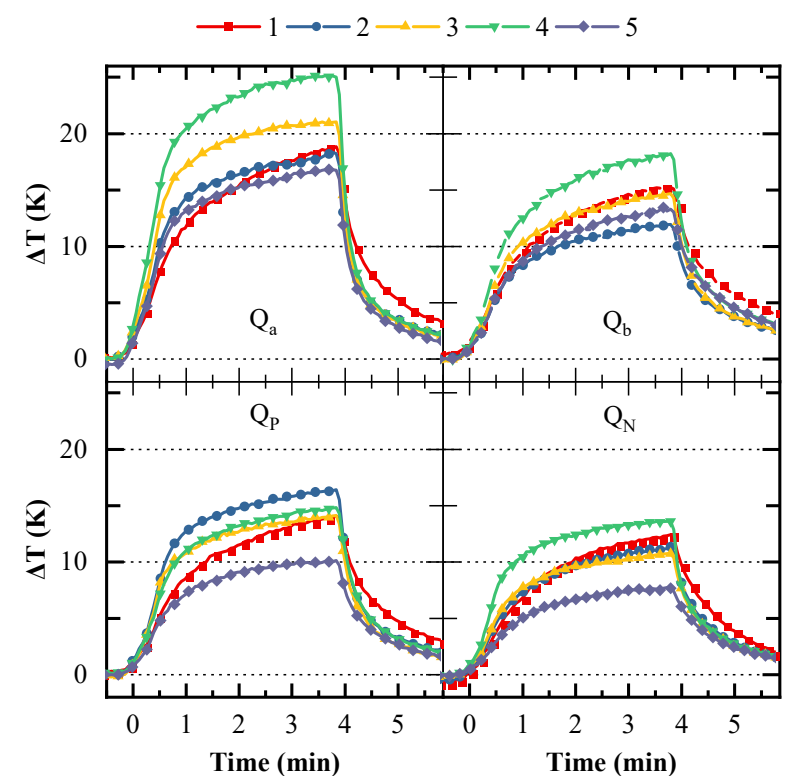

Fig. 18. Transient temperature rises between the device and the coolant inlet temperature at $1 \mathrm{~kW}$ transferred power for all 20 transistors.

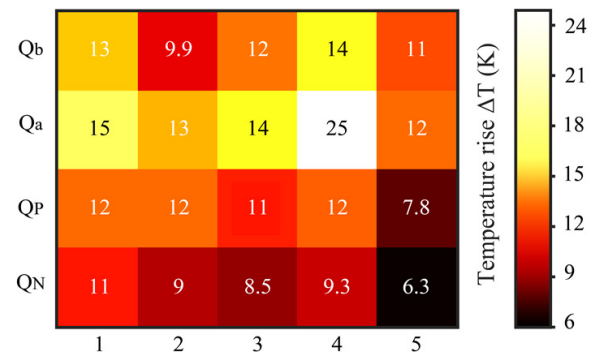

Fig. 19. Temperature map (maximum $\Delta T$ between the device temperature and the coolant inlet $[\mathrm{K}]$ ) of the converter at a transferred power of $1 \mathrm{~kW}$.

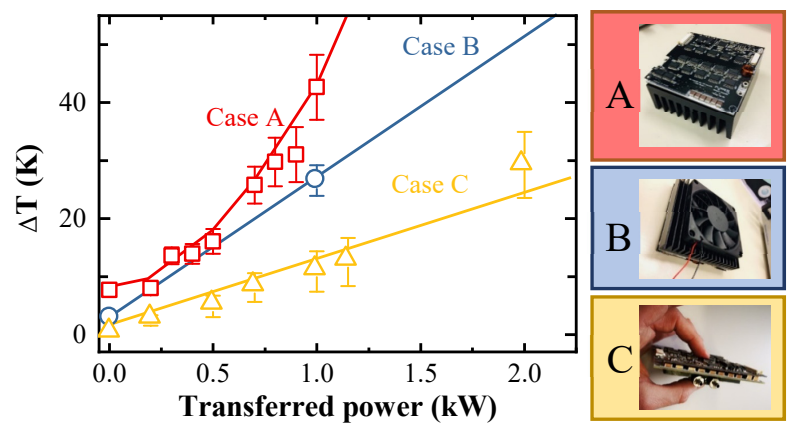

Fig. 20. Temperature rise between the device and the coolant inlet temperature versus converter power for Case A: Converter with aluminum heat sink, Case $B$ : Converter with heat sink and fan and Case $C$ : Converter with 3D-printed microfluidic heat sink. Error bars indicate the standard deviation of all 20 temperatures measured on the converter per data point.

conventional heat sinks. Three cases were evaluated, as shown in Fig. 20: In Case $A$ no fan was used, in Case $B$ a fan was added with a flow rate of $1.0 \mathrm{~m}^{3} / \mathrm{min}$ and in Case $C$ the $3 \mathrm{D}$ printed manifold heat sink was evaluated. Fig. 20 shows the average temperature rise for these three scenarios, revealing the much more efficient cooling of the proposed microfluidic heat sink. For a $1 \mathrm{~kW}$ of transferred power, Case $A$ showed an average
TABLE VI

DIMENSIONS, PROPERTIES AND POWER DENSITIES FOR THE CONSIDERED DESIGNS

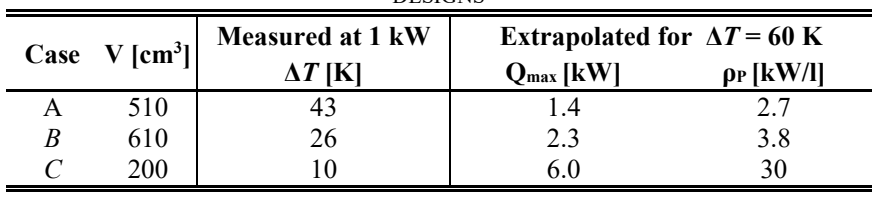

temperature rise of 43 degrees, which was reduced to $26 \mathrm{~K}$ in Case $B$ and in Case $C$ the average temperature rise was only 10 $\mathrm{K}$. The offset in temperature rise at zero transferred power for Cases $A$ and $B$ was due to the constant losses in the power supplies that drive the transistors.

Table VI summarizes the volume and thermal resistance of the evaluated designs. The maximum power was calculated using the measured thermal resistances and a maximum temperature rise of $60 \mathrm{~K}$. This extrapolation of converter power is justified since the converter efficiency was constant over the entire range of converter power [39]. As can be seen, by moving from an air-cooled converter to a liquid-cooled converter, the maximum converter power can theoretically be increased from $1.4 \mathrm{~kW}$ to $6 \mathrm{~kW}$, which results in a more than 10 -fold increase in power density, $\rho_{P}$, up to $30 \mathrm{~kW} / 1$, revealing the clear benefit of this new cooling technique.

\section{Discussion}

The microfluidic manifold heat sink can handle higher heat loads in a smaller volume compared to conventional air-cooled approaches and is therefore a promising approach for high power density application. However, the evaluated converter was not specifically designed to have equal losses over all transistors, causing a large temperature spread as observed in Fig. 19. The single outlier at $\mathrm{Q}_{\mathrm{a} 4}$ limits the maximum power in the current setup, which raises an interesting possibility for design optimization. If the power dissipation per components is known, cold-plates with customized geometries can be designed for each transistor to achieve a uniform temperature distribution. Equal temperature distribution can easily be obtained by increasing the number of parallel channels on the devices with high heat loads and by reducing the number of channels on the devices with low heat loads. Changing the number of channels modulates the flow rate at equal pressure drop as well as the effective surface area for heat transfer. Following this approach, heat sinks can be sized in the same way as transistors and passive components to achieve an optimum design, which adds a new layer of co-engineering to the design process.

\section{CONCLUSION}

In this work, we presented a compact microfluidic cooling solution that offers high performance cooling at low energy consumption, which helps reducing pump size. This cooling system consisted of silicon cold-plates with micrometer-sized channels and a manifold that distributes coolants to the hotspots on the PCB. Analytical models demonstrated the importance of optimizing the microchannel size to achieve a high COP. The required manifold channel cross-section depends strongly on the selected microchannel width. These 
findings offer important design guidelines to adapt this technology for practical applications.

Two manifolds have been realized to demonstrate the possibilities of low-cost manufacturing and rapid prototyping. The concept of a microchannel cold-plate manifold heat sink was demonstrated on a switched capacitor DC-DC converter with $20 \mathrm{GaN}$ transistors. Experimental evaluation showed that up to $600 \mathrm{~W}$ of dissipated power could be extracted, while keeping the junction temperature rise on the transistors below $60 \mathrm{~K}$. By using this microfluidic cooling system, the converter can reach a power density of $30 \mathrm{~kW} / \mathrm{cm}^{3}$, while requiring less than $1 \mathrm{~W}$ of pumping power for cooling. This cooling system offers a new design approach, where microchannel cold-plates can be selected together with the power devices. We believe that this extra layer of optimization and design flexibility bridges the gap between electric design and thermal management which helps increasing power density in future power electronics applications.

\section{REFERENCES}

[1] H. Ohashi, I. Omura, S. Matsumoto, Y. Sato, H. Tadano, and I. Ishii, "Power electronics innovation with next generation advanced power devices," in IEICE Transactions on Communications, 2004, vol. E87-B, no. 12, pp. 3422-3429.

[2] G. J. Su, "Comparison of $\mathrm{Si}, \mathrm{SiC}$, and $\mathrm{GaN}$ based Isolation Converters for Onboard Charger Applications," in 2018 IEEE Energy Conversion Congress and Exposition, ECCE 2018, 2018, pp. 1233-1239.

[3] J. Biela, U. Badstuebner, and J. W. Kolar, "Impact of power density maximization on efficiency of DC-DC converter systems," IEEE Trans. Power Electron., vol. 24, no. 1, pp. 288-300, 2009.

[4] R. M. Abdul Khadar, C. Liu, R. Soleimanzadeh, and E. Matioli, "Fully Vertical GaN-on-Si power MOSFETs," IEEE Electron Device Lett., vol. 40, no. 3, pp. 443-446, Mar. 2019.

[5] J. Ma, C. Erine, P. Xiang, K. Cheng, and E. Matioli, "Multi-channel tri-gate normally-on/off AlGaN/GaN MOSHEMTs on Si substrate with high breakdown voltage and low ON-resistance," Appl. Phys. Lett., vol. 113, no. 24, p. 242102, Dec. 2018.

[6] A. Bar-Cohen, J. J. Maurer, and D. H. Altman, "Gen3 embedded cooling for high power RF components," in 2017 IEEE International Conference on Microwaves, Antennas, Communications and Electronic Systems (COMCAS), 2017, pp. 18 .

[7] A. Bar-Cohen, J. J. Maurer, and A. Sivananthan, "Near-junction microfluidic thermal management of RF power amplifiers," in 2015 IEEE International Conference on Microwaves, Communications, Antennas and Electronic Systems (COMCAS), 2015, pp. 1-8.

[8] B. Agostini, M. Fabbri, J. E. Park, L. Wojtan, J. R. Thome, and B. Michel, "State of the Art of High Heat Flux Cooling Technologies," Heat Transf. Eng., vol. 28, no. 4, pp. 258-281, Apr. 2007.

[9] J. W. Pomeroy, M. J. Uren, B. Lambert, and M. Kuball, "Operating channel temperature in GaN HEMTs: DC versus RF accelerated life testing," Microelectron. Reliab., vol. 55, no. 12, pp. 2505-2510, Dec. 2015.

[10] A. M. Darwish, B. D. Huebschman, E. Viveiros, and H. A. Hung, "Dependence of GaN HEMT Millimeter-Wave Performance on Temperature," IEEE Trans. Microw. Theory Tech., vol. 57, no. 12, pp. 3205-3211, Dec. 2009

[11] Y. Lei et al., "A 2-kW Single-Phase Seven-Level Flying Capacitor Multilevel Inverter With an Active Energy Buffer," IEEE Trans. Power Electron., vol. 32, no. 11, pp. 8570-8581, Nov. 2017.

[12] S. Debnath, J. Qin, B. Bahrani, M. Saeedifard, and P. Barbosa, "Operation, Control, and Applications of the Modular Multilevel Converter: A Review," IEEE Trans. Power Electron., vol. 30, no. 1, pp. 37-53, Jan. 2015.

[13] H. Chen, H. Kim, R. Erickson, and D. Maksimovic, "Electrified
Automotive Powertrain Architecture Using Composite DC-DC Converters," IEEE Trans. Power Electron., vol. 32, no. 1, pp. 98116, Jan. 2017.

[14] A. J. Blodgett and D. R. Barbour, "Thermal Conduction Module: A High-Performance Multilayer Ceramic Package," IBM J. Res. Dev., vol. 26, no. 1, pp. 30-36, Jan. 1982

[15] Y. Zeng, A. Hussein, and A. Castellazzi, "Individual device active cooling for enhanced system-level power density and more uniform temperature distribution," in 2018 IEEE 30th International Symposium on Power Semiconductor Devices and ICs (ISPSD), 2018, pp. 471-474.

[16] N. Pallo et al., "Modular heat sink for chip-scale GaN transistors in multilevel converters," in Conference Proceedings - IEEE Applied Power Electronics Conference and Exposition - APEC, 2018, vol. 2018-March, pp. 2798-2805.

[17] T. Wei et al., "High-Efficiency Polymer-Based Direct Multi-Jet Impingement Cooling Solution for High-Power Devices," IEEE Trans. Power Electron., vol. 34, no. 7, pp. 6601-6612, Jul. 2019.

[18] J. Jorg, S. Taraborrelli, G. Sarriegui, R. W. De Doncker, R. Kneer, and W. Rohlfs, "Direct Single Impinging Jet Cooling of a mosfet Power Electronic Module," IEEE Trans. Power Electron., vol. 33, no. 5, pp. 4224-4237, May 2018

[19] Y. Han, B. L. Lau, G. Tang, and X. Zhang, "Thermal Management of Hotspots Using Diamond Heat Spreader on Si Microcooler for GaN Devices," IEEE Trans. Components, Packag. Manuf. Technol., vol. 5, no. 12, pp. 1740-1746, Dec. 2015.

[20] D. B. Tuckerman and R. F. W. Pease, "High-performance heat sinking for VLSI," IEEE Electron Device Lett., vol. 2, no. 5, pp. 126-129, May 1981.

[21] S. G. Kandlikar and H. R. Upadhye, "Extending the heat flux limit with enhanced microchannels in direct single phase cooling of computer chips," Semicond. Therm. Meas. Manag. IEEE Twenty First Annu. IEEE Symp. 2005., pp. 8-15, 2005.

[22] G. M. Harpole and J. E. Eninger, "Micro-channel heat exchanger optimization," in 1991 Proceedings, Seventh IEEE Semiconductor Thermal Measurement and Management Symposium, 2002, pp. 5963.

[23] D. Copeland, M. Behnia, and W. Nakayama, "Manifold microchannel heat sinks: Isothermal analysis," IEEE Trans. Components Packag. Manuf. Technol. Part A, vol. 20, no. 2, pp. 96 102, Jun. 1997.

[24] J. . H. Ryu, D. . H. Choi, and S. . J. Kim, "Three-dimensional numerical optimization of a manifold microchannel heat sink," Int. J. Heat Mass Transf., vol. 46, no. 9, pp. 1553-1562, Apr. 2003.

[25] M. Ohadi, K. Choo, S. Dessiatoun, and E. Cetegen, "Next Generation Microchannel Heat Exchangers," in SpringerBriefs in Applied Sciences and Technology, no. 9781461407782, New York, NY: Springer New York, 2013, pp. 1-111.

[26] L. Everhart, N. Jankowski, B. Geil, A. Bayba, D. Ibitayo, and P. McCluskey, "Manifold Microchannel Cooler for Direct Backside Liquid Cooling of $\mathrm{SiC}$ Power Devices," in ASME 5th International Conference on Nanochannels, Microchannels, and Minichannels, 2007, pp. 285-292.

[27] W. Escher, T. Brunschwiler, B. Michel, and D. Poulikakos, "Experimental Investigation of an Ultrathin Manifold Microchannel Heat Sink for Liquid-Cooled Chips," J. Heat Transfer, vol. 132, no. 8, p. 081402, Aug. 2010.

[28] R. J. Phillips, "Forced-convection, liquid-cooled, microchannel heat sinks," MIT, 1987.

[29] X. F. Peng and G. P. Peterson, "Convective heat transfer and flow friction for water flow in microchannel structures," Int. J. Heat Mass Transf., vol. 39, no. 12, pp. 2599-2608, Aug. 1996.

[30] X. F. Peng and G. P. Peterson, "The effect of thermofluid and geometrical parameters on convection of liquids through rectangular microchannels," Int. J. Heat Mass Transf., vol. 38, no. 4, pp. 755758, Mar. 1995.

[31] V. K. Samalam, "Convective heat transfer in microchannels," $J$. Electron. Mater., vol. 18, no. 5, pp. 611-617, Sep. 1989.

[32] S. J. Kim, "Methods for thermal optimization of microchannel heat sinks," Heat Transf. Eng., vol. 25, no. 1, pp. 37-49, 2004.

[33] J. H. Ryu, D. H. Choi, and S. J. Kim, "Numerical optimization of the thermal performance of a microchannel heat sink," Int. J. Heat 
Mass Transf., vol. 45, no. 13, pp. 2823-2827, Jun. 2002.

[34] R. K. Shah and A. L. (Alexander L. London, Laminar flow forced convection in ducts : a source book for compact heat exchanger analytical data. Academic Press, 1978.

[35] "GS66508T Top-side cooled 650 V E-mode GaN transistor Preliminary Datasheet," 2009.

[36] "GS61008T Top-side cooled 100 V E-mode GaN transistor Preliminary Datasheet," 2009.

[37] S. A. Solovitz and J. Mainka, "Manifold Design for Micro-Channel Cooling With Uniform Flow Distribution," J. Fluids Eng., vol. 133, no. 5 , p. 051103 , May 2011 .

[38] D. R. Emerson, K. Cieślicki, X. Gu, and R. W. Barber, "Biomimetic design of microfluidic manifolds based on a generalised Murray's law," Lab Chip, vol. 6, no. 3, p. 447, Feb. 2006.

[39] G. Kampitsis, R. van Erp, and E. Matioli, "Ultra-High Power Density Magnetic-less DC / DC Converter Utilizing GaN Transistors," 2019 IEEE Appl. Power Electron. Conf. Expo., pp. 1609-1615, Mar. 2019.

[40] W. Qian, D. Cao, J. G. Cintron-Rivera, M. Gebben, D. Wey, and F. Z. Peng, "A Switched-Capacitor DC-DC Converter With High Voltage Gain and Reduced Component Rating and Count," IEEE Trans. Ind. Appl., vol. 48, no. 4, pp. 1397-1406, Jul. 2012.

[41] Dong Cao and Fang Zheng Peng, "Zero-current-switching multilevel modular switched-capacitor dc-dc converter," in 2009 IEEE Energy Conversion Congress and Exposition, 2009, pp. 35163522 .

[42] F. Z. Peng, M. L. Gebben, and B. Ge, "A compact nX DC-DC converter for photovoltaic power systems," in 2013 IEEE Energy Conversion Congress and Exposition, 2013, pp. 4780-4784.

[43] J. Joh, J. A. del Alamo, U. Chowdhury, T.-M. Chou, H.-Q. Tserng, and J. L. Jimenez, "Measurement of Channel Temperature in GaN High-Electron Mobility Transistors," IEEE Trans. Electron Devices, vol. 56, no. 12, pp. 2895-2901, Dec. 2009.

[44] L. Dupont, Y. Avenas, and P.-O. Jeannin, "Comparison of Junction Temperature Evaluations in a Power IGBT Module Using an IR Camera and Three Thermosensitive Electrical Parameters," IEEE Trans. Ind. Appl., vol. 49, no. 4, pp. 1599-1608, Jul. 2013. 